\title{
Nailfold capillaroscopic findings in patients with Raynaud's phenomenon: Preliminary report
}

\author{
Binit Vaidya*, Manisha Bhochhibhoya \\ National Center for Rheumatic Diseases (NCRD) \\ Ratopul, Kathmandu-9, Nepal
}

\section{DOI Name}

http://dx.doi.org/10.3126/jaim.v4i1.14175

\section{Keywords \\ capillaroscopy; raynaud phenomenon; scleroderma \\ Citation \\ Bajracharya MR, Bhattarai MD, Karki BB, Prajapati S, Karmacharya D, Manandhar S, Rajouria $A D$. Nailfold capillaroscopic findings in patients with Raynaud's phenomenon: Preliminary report. Journal of Advances in Internal Medicine 2015;04(01):13-15.}

\section{ABSTRACT}

Back grounds and Aims: Microvascular involvement of nailfold often occurs in systemic rheumatic diseases, especially scleroderma and related conditions. Nailfold capillaroscopy is easily performed non-invasive, simple, repeatable, sensitive, safe and inexpensive method to examine nailfold architecture by microscope.The normal capillaries are thin, symmetrical and have hair-pin appearance. Anomalies include dilated capillary loops, dropouts, tortuosity, avascular area, arborifications, megacapillaries, infracts,thrombsis and haemorrhages. This study aims to see the morphological changes in microcirculation in nailfolds of patients with Raynaud's, which can be helpful in predicting the presence of connective tissue disorder.

Methods: It is an observational study conducted at National Center for Rheumatic Diseases, Kathmandu from 26 ${ }^{\text {th }}$ March 2014 to $30^{\text {th }}$ March 2015. Nailfolds of 8 fingers of both hands in 105 patients were examined using a hand held microscope.

Results: Of 105 patients, 91 patients (86.6\%) had abnormal morphological changes while 14 (13.4\%) had no significant changes in microvessels. Normal patients had no underlying connective tissue disease(CTD) but those with abnormal findings had proven underlying CTD which included Lupus 6.5\%, Scleroderma 17.5\%, Rheumatoid Arthritis 14.2\%, Mixed CTD7.6\%, Undifferentiated CTD1.0\%, Undifferentiated inflammatory arthritis $14.2 \%$, Psorasis $1.0 \%$, Rheumatoid Arthritis with scleroderma overlap 4.3\%. No primary diagnosis was found in $32.9 \%$ of patients.

Conclusion: Nailfold capillaroscopy allows direct examination of microvascular structure of a patient. Abnormal findings in a patient with Raynaud's phenomenon might help to identify the presence of or future evolution into systemic connective tissue disorder.

\section{BACKGROUND}

Raynaud's phenomenon (RP) can occur with or without systemic involvement. RP is the initial presentation in many connective tissue diseases. ${ }^{1-3}$ Microvascular changes in nailfold capillaries often occurs in systemic rheumatic diseases like scleroderma(SSc), lupus etc. ${ }^{4,5}$
Nailfold capillaroscopy is easily performed non-invasive, reproducible and inexpensive method to examine nailfold

\footnotetext{
* Corresponding author

Dr Binit Vaidya (MD, FACR)

Rheumatologist,

National Center for Rheumatic Diseases (NCRD)

Ratopul, Kathmandu-9, Nepal

Email: drbinitvaidya@yahoo.com
} 
architecture.The normal capillaries are thin, symmetrical with hair-pin appearance. Anomalies include dilated capillary loops, dropouts, tortuosity, avascular area, arborifications, megacapillaries, infarcts, thrombosis and haemorrhages [figure 1]. ${ }^{6,7}$ Distinguishing primary and secondary RP is important in making a treatment plan and prognosis of a patient.

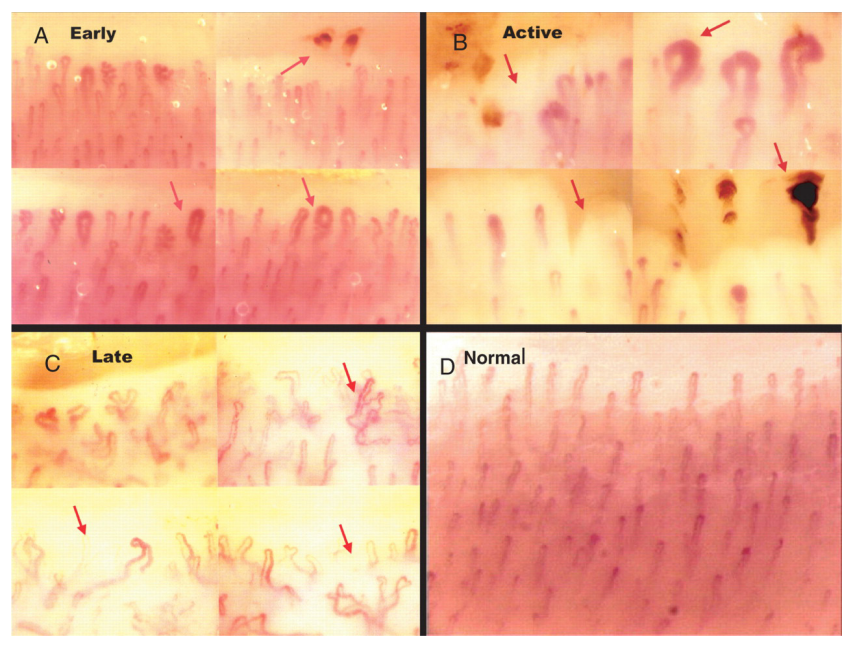

Figure 1:

We aim to examine morphological changes in microcirculation in nailfolds of patients with Raynaud's which would help in predicting the presence of rheumatic disease.

\section{METHODOLOGY}

This is a single center cross-sectional observational study conducted at National Center for Rheumatic Diseases (NCRD), Kathmandu from 26 th March 2014 to $30^{\text {th }}$ March 2015. Consecutive patients with complaints of Raynaud's phenomenon (intermittent pallor, coldness or cyanosis of digits) were included. Those with diabetes mellitus were excluded.

Nailfolds of 8 fingers were examined using a digital capillaroscope. Patients were rested at a room temperature of $20-22^{\circ} \mathrm{C}$ for $15-20$ minutes. A drop of immersion oil is placed on the cuticle of the fingers.Fingers affected by recent trauma were not analyzed.

\section{RESULTS}

A total of 105 patients were included in the study. Any capillary abnormality was seen in 91 patients (86.6\%), whereas 14 (13.4\%) had no significant changes. Normal patients had no underlying connective tissue disease (CTD). Of those with abnormal findings, $32.9 \%$ did not have any other primary diagnosis. Others were diagnosed with various underlying rheumatic disease as illustrated in figure2. Lupus, scleroderma, rheumatoid arthritis and mixed connective tissue disease (MCTD) constituted the main underlying diagnoses.

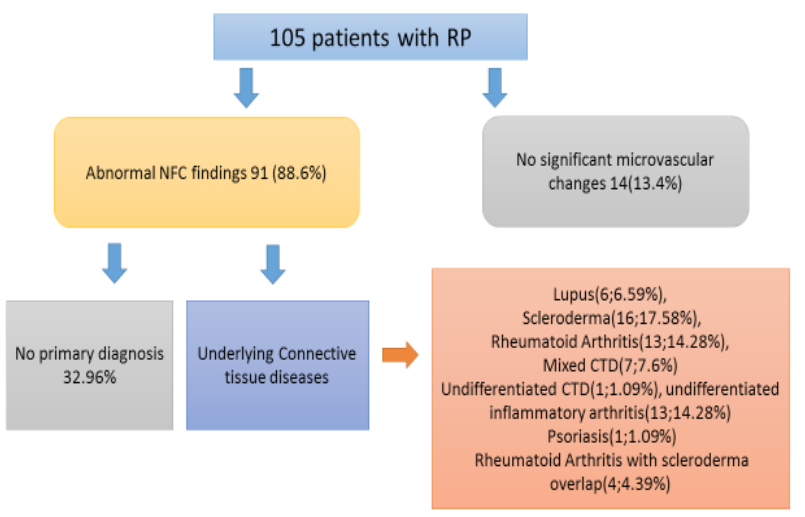

Figure 2:

\section{DISCUSSION}

Raynaud's phenomenon is a common symptom occurring in 3-5\% of general population, with a higher prevalence in women than in men. ${ }^{8}$ Many people with RP may not have underlying connective tissue disease or any other secondary cause (Primary RP). The diagnostic criteria for primary RP include normal NFC findings. ${ }^{9,10}$ Rest of those with RP is likely to have an underlying cause. ${ }^{8}$ Connective tissue disorders are associated with and often present with RP. Diseases like lupus, scleroderma, MCTD, dermatomyositis are commonly associated with RP. ${ }^{5}$ Patients with such disorders have microvascular structural abnormality that can be detected on capillaroscopic examination (NFC). It is necessary and helpful in an individual patient with RP to identify such underlying disorders as it will have implications in prognosis and further management of these patients. ${ }^{1}$

Recent studies have described two fold role of NFC in rheumatology. ${ }^{11,12}$ First, it has a role in differential diagnosis of patients with RP. Second, it may have a role in the prediction of clinical complications in CTDs.In scleroderma, pilot studies have shown predictive associations of nailfold capillary changes with peripheral vascular and lung involvement hinting at a role of capillaroscopy as putative biomarker. ${ }^{13}$

A meta-analysis studying factors predicting transition from primary to secondary RP showed that an abnormal NFC finding had a predictive value of $47 \%$ followed by a positive ANA (30\%) to predict transition to secondary RP. Our study was not designed to follow patients with primary RP but was designed to identify the presence of underlying CTD in patients with RP. ${ }^{2}$ In our study, $58 \%$ of those with any RP had underlying connective tissue disease.

There are various other studies since then to show that NFC 
has a crucial role in monitoring the transition from primary to secondary RP. ${ }^{13-16}$ In scleroderma, NFC findings can actually correlate with the early, active or late stages of the disease..$^{12}$ Whereas, in disorders like scleroderma, MCTD, dermatomyositis etc these abnormalities can predict pulmonary involvement. ${ }^{17}$ Though not used commonly in practice, NFC has an important role in various diseases of rheumatology and its utility is not only limited to patients with RP. ${ }^{18}$

Not only does it help to predict the presence of connective tissue disorder in patients with RP, it is also useful to reliably rule out pathological RP. Most of these patients are overinvestigated and treated due to lack of confidence in diagnosing primary RP. A perfectly normal NFC with addition of a negative

\section{REFERENCES}

1. Hirschl M, Hirschl K, Lenz $M$, et al. Transition from primary Raynaud's phenomenon to secondary Raynaud's phenomenon identified by diagnosis of an associated disease: results of ten years of prospective surveillance. Arthritis Rheum. 2006;54:1974-81.

2. Spencer-Green G. Outcomes in primary Raynaud phenomenon: a meta-analysis of the frequency, rates, and predictors of transition to secondary diseases. Archives of internal medicine. 1998;158:595-600.

3. Herrick AL. The pathogenesis, diagnosis and treatment of Raynaud phenomenon. Nat Rev Rheumatol. 2012;8:46979.

4. Herrick AL. Pathogenesis of Raynaud's phenomenon. Rheumatology (Oxford). 2005;44:587-96.

5. Grassi W, De Angelis R. Capillaroscopy: questions and answers. ClinRheumatol. 2007;26:2009-16.

6. Maricq HR, LeRoy EC. Patterns of finger capillary abnormalities in connective tissue disease by "widefield" microscopy.Arthritis Rheum. 1973;16:619-28.

7. Maricq HR, LeRoy EC, D'Angelo WA et al. Diagnostic potential of in vivo capillary microscopy in scleroderma and related disorders. Arthritis Rheum. 1980;23:183-9.

8. Valdovinos ST, Landry GJ. Raynaud Syndrome. Techniques in vascular and interventional radiology. 2014;17:241-6.

9. LeRoy EC, Medsger TA, Jr. Raynaud's phenomenon: a proposal for classification. ClinExpRheumatol. 1992;10:485-8.

10. Maverakis E, Patel F, Kronenberg DG et al. International consensus criteria for the diagnosis of Raynaud's phenomenon. J Autoimmun. 2014;48:60-5.
ANA test can reliably rule out the presence of any underlying rheumatic disease. ${ }^{2}$

We did not try to correlate any specific NFC abnormality with any particular rheumatic disease because of small number of patients in each specific diagnosis.

\section{CONCLUSION}

NFC examination is a simple and non-invasive method to evaluate patients with RP. It has a major role in predicting the presence of or evolution to a secondary underlying connective tissue disease and to decide when to stop investigating a patient with Raynaud's phenomenon.

11. Houtman N. Nailfoldvideocapillaroscopy assessment of microvascular damage in systemic sclerosis. J Rheumatol. 2000;27:2722-3.

12. Cutolo $M$, Sulli $A$, Pizzorni $C$ et al. Nailfoldvideocapillaroscopy assessment of microvascular damage in systemic sclerosis. J Rheumatol. 2000;27:15560.

13. Cutolo $M$, Smith V. State of the art on nailfoldcapillaroscopy: a reliable diagnostic tool and putative biomarker in rheumatology? Rheumatology (Oxford). 2013;52:1933-40.

14. Herrick AL, Cutolo M. Clinical implications from capillaroscopic analysis in patients with Raynaud's phenomenon and systemic sclerosis. Arthritis Rheum. 2010;62:2595-604.

15. Rossi D, Russo A, Manna Eet al. The role of nailvideocapillaroscopy in early diagnosis of scleroderma. Autoimmun Rev. 2013;12:821-5.

16. Koenig M, Joyal F, Fritzler MJ et al. Autoantibodies and microvascular damage are independent predictive factors for the progression of Raynaud's phenomenon to systemic sclerosis: a twenty-year prospective study of 586 patients, with validation of proposed criteria for early systemic sclerosis. Arthritis Rheum. 2008;58:390212.

17. de HolandaMafaldo Diogenes A, Bonfa E, Fuller Retal. Capillaroscopy is a dynamic process in mixed connective tissue disease. Lupus. 2007;16:254-8.

18. Cutolo M, Sulli A, Secchi ME et al. The contribution of capillaroscopy to the differential diagnosis of connective autoimmune diseases. Best practice \& research Clinical rheumatology. 2007;21:1093-108. 